\title{
Effect of Restriction of Foods with High Fructose Corn Syrup Content on Metabolic Indices and Fatty Liver in Obese Children
}

\author{
Lorena del Rocio Ibarra-Reynoso Hilda Lissette López-Lemus \\ Ma Eugenia Garay-Sevilla Juan Manuel Malacara \\ Department of Medical Sciences, University of Guanajuato, Campus León, León, Mexico
}

\section{Keywords}

Fructose $\cdot$ Obesity $\cdot$ Hepatic steatosis

\begin{abstract}
Objective: We examined the effect of restriction of foods with high fructose content in obese school children. Methods: In a clinical study, we selected 54 obese children 6 to 11 years old with high fructose consumption ( $>70 \mathrm{~g} /$ day) in order indicate dietary fructose restriction $(<20$ $\mathrm{g} /$ day) for 6 weeks. Anthropometry, liver ultrasound as well as glucose, insulin, lipids, leptin, IGFBP1, and RBP4 serum levels were collected. Results: The group of children had $80 \%$ adherence and reported decreased fructose consumption (110 \pm 38.6 to $11.4 \pm 12.0 \mathrm{~g} /$ day) and also a significant decrease in caloric $(2,384 \pm 568$ to $1,757 \pm 387 \mathrm{kcal} /$ day $)$ and carbohydrate consumption (302 \pm 80.4 to $203 \pm 56.0 \mathrm{~g} /$ day). The severity of steatosis improved significantly after fructose restriction $(\mathrm{p}<0.000001)$. However, no changes in BMI, systolic blood pressure, or diastolic blood pressure were found. Only triglyceride levels decreased (1.44 \pm 0.43 to 1.31 $\pm 0.38 \mathrm{mmol} / \mathrm{l})$, High-densitiy lipoprotein cholesterol showed a marginal increase (1.45 \pm 0.19 to $1.56 \pm 0.44 \mathrm{mmol} / \mathrm{l})$. Insulin resistance and RBP4 did not change. Conclusions: In school children, the restriction of high fructose foods with a decrease of caloric and carbohydrate intake at 6 weeks did not induce weight loss; however, triglyceride levels and hepatic steatosis decreased. Differences with other studies in regard to weight loss may be explained by adaptive changes on metabolic expenditure.

(C) 2017 The Author(s)

Published by S. Karger GmbH, Freiburg
\end{abstract}




\section{Introduction}

Fructose is a monosaccharide present in fruits and syrup. Sucrose has been replaced by inexpensive, sweet high fructose corn-based syrups in our diet that meanwhile amount to $40 \%$ of all added caloric sweeteners [1]. Abundant information shows that a high consumption of fructose corn syrup may increase triglyceride levels, decrease insulin sensitivity [2], and promote visceral adiposity [3]. Furthermore, evidence shows that the acute ingestion of 60-75 g/day fructose corn syrup is also associated with dyslipidemia, worsening of blood pressure, and insulin resistance in obese children [4] and adolescents [5]. The increased fructose ingestion associated with fatty liver disease is also reported [6].

Fructose is metabolized in other pathways than glucose. The formation of fructose 1-phosphate is not reversible, and this metabolite is a substrate for de novo lipogenesis. Fructose intake also promotes glucose production as well as impairment of hepatic ATP recovery [7], with mitochondrial dysfunction and endoplasmic reticulum stress. These two factors may be involved in the formation of non-alcoholic fatty liver disease (NAFLD) [8]. Moreover, fructose is absorbed and delivered to the liver in much higher concentrations as compared to other tissues. Fatty liver disease is considered a precursor [9] for the development of metabolic disease.

NAFLD is the most common cause of chronic liver disease, which includes a spectrum ranging from simple steatosis to progressive nonalcoholic steatohepatitis with or without cirrhosis [10]. NAFLD is frequently associated with obesity, may appear early in life, and increases with age [11]. It also has been related to retinol binding protein-4 (RBP4) and is associated with whole body and hepatic insulin resistance measured by homeostatic model assessment-insulin resistance (HOMA-IR) and insulin like growth factor binding protein 1 (IGFBP1) respectively [12]. This process is mediated by inflammation [13], and visceral adiposity [14].

Pediatric NAFLD may show different characteristics to adult NAFLD, mainly in terms of histology [15, 16], prevalence, diagnostic features, and management [17]. It remains to be determined if there are possible differences in natural history, etiopathogenesis, prognosis, or response to treatment. Therefore, detailed studies about NAFLD in pediatric patients are urgently needed.

Given the high fructose consumption in the Mexican population ( $>70-168 \mathrm{~g} /$ day) $[18,19]$ and its association with obesity, insulin resistance and NAFLD, the effect of fructose restriction needs a full exploration. Studies on the effect of fructose restriction show conflicting results $[18,20]$. In the present study, we studied obese children with and without NAFLD and with high daily fructose intake who were pescribed to a restriction of foods and drinks with high fructose corn syrup while recommending to avoid other modifications on previous food intake. We examined the effect of this restriction on weight, fatty liver as well as metabolic and hormone levels.

\section{Material and Methods}

We carried out a clinical, longitudinal, study in 54 obese children 6 to11 years old (27 females and 27 males). The participants were recruited from grammar schools from the city of León, Mexico. They were apparently healthy, did not receive any nutritional treatment, and consumed more than $70 \mathrm{~g}$ fructose per day. In the group of girls $25(92.6 \%)$ were at pre-menarche, and only 2 girls (7.4\%) were at post-menarche.

Selected children had normal glucose levels, stable weight, and normal blood pressure. The two girls at post-menarche had regular menstrual cycles and no hirsutism.

Children were considered obese if their equivalents to adult BMI, after adjustment for gender and age, were higher than $30 \mathrm{~kg} / \mathrm{m}^{2}$, according to the international tables of Cole et al. [21]. 
To identify children from grammar schools with high fructose corn syrup consumption ( $>70 \mathrm{~g} /$ day), a screening of 108 children was carried out by experienced personnel, calculating food consumption with a 24-hour dietary recall. Obese children with high fructose consumption were invited. Those who accepted participation were instructed to continue their usual diet but to eliminate foods and drinks with high fructose corn syrup content. The fructose was restricted to a maximum of $20 \mathrm{~g} /$ day for 6 weeks, as reported in previous studies in children [20].

\section{Data Collection}

The group was evaluated at baseline and after 6 weeks by collecting clinical and anthropometric data, and a fasting blood sample for hormones and metabolites. Hepatic steatosis was assessed by ultrasound.

Waist girth, weight, and standing height were obtained by trained personnel according to standard techniques [22], and BMI was calculated.

A venous blood sample was obtained after $12 \mathrm{~h}$ fasting to measure glucose, triglycerides, and cholesterol by conventional methods. Insulin (ALPCO, Salem, NH, USA), leptin (ALPCO), and RBP4 (RayBiotech, Norcross, GA, USA) were measured by ELISA with intra- and inter-assay variation coefficients of $2.7 \%$ and $5.8 \%$ for insulin, $6.0 \%$ and $8.0 \%$ for leptin, $6.1 \%$ and $7.0 \%$ for IGFBP1, and $5.9 \%$ and $5.6 \%$ for RBP4. Insulin resistance was considered with HOMA-IR $>2.67$ for boys and $>2.22$ for girls [23].

\section{Liver Ultrasound}

Fatty liver was assessed by ultrasound, an appropriate and practical method [24]. The procedure was carried out by a physician radiologist using a General Electric Logic 400 MD (General Electric, Boston, MA, USA) with a convex transducer of 3.6 MHz. The results were assessed by two experienced radiologists, classifying the extent of liver steatosis in four groups according to Mittelstaedt [25]: negative, slight, moderate and severe.

\section{Diet Evaluation}

Food intake was evaluated with a 24-hour dietary recall for 3 days (two at midweek and one at weekend). In all cases, 24-hour dietary recall (before and after interventions) was carried out by a certified nutritionist and answered by the child and at least one parent. Macronutrients were quantified using the NutriKcal ${ }^{\circledR}$ (Nitrical, Mexico City, Mexico) program. Fructose consumption was evaluated according to Matthews et al. [26], using the SNUT program [27].

According to the study protocol, children are to be excluded from the study when their adherence in terms of fructose consumption was less than $80 \%$ or if they reported an intercurrent disease, and to be replaced by a new volunteer. Adherence to the diet was assessed with a 24-hour dietary recall conducted 3 days/week (two at midweek and one at weekend).

\section{Ethics}

When candidates met inclusion criteria, the nature and purpose of the study was explained to them and at least one of their parents. If both the child and the parent or tutor accepted, they signed informed consent; confidentiality of individual results was guaranteed. The study meets the standards of the Declaration of Helsinki and was approved by the Institutional Ethics Committee.

\section{Statistical Analysis}

We described continuous variables with means and standard deviations, and discrete variables with percentages, and used the Komogorov-Smirnov test to examine normal distribution.

The effect of the intervention on the variables studied was analyzed by a paired t-test. Changes $(\Delta)$ in the stages of fatty liver were assessed using a chi-square test. We examined the factors associated with $\Delta$ in dietary fructose, i.e. HOMA-IR, RBP4 and leptin, with a stepwise forward multiple regression procedure taking as candidate regressors, age, and $\Delta \mathrm{BMI}$, waist girth, systolic and diastolic blood pressure, glucose, triglycerides, total cholesterol, high-density lipoprotein cholesterol (HDL-cholesterol), low-density lipoprotein cholesterol (LDL-cholesterol), and IGFBP1 levels. Factors related to changes in steatosis gradation were examined with ANOVA. The Statistics V5 (X-formation, Tilst, Denmark) software was used. Significance was considered at $\mathrm{p}<0.05$. 
Table 1. Basal anthropometric, metabolic and hormonal characteristics before and after restriction of fructose-rich food

\begin{tabular}{lllll}
\hline & $\begin{array}{l}\text { Basal } \\
(\mathrm{n}=54)\end{array}$ & $\begin{array}{l}6 \text { weeks } \\
(\mathrm{n}=54)\end{array}$ & $\mathrm{t}$ & $\mathrm{p}$ \\
\hline BMI, kg/m² & $26.3 \pm 2.7$ & $26.3 \pm 2.9$ & 0.74 & 0.46 \\
Waist girth, cm & $86.9 \pm 7.3$ & $86.9 \pm 7.4$ & 0.35 & 0.73 \\
Systolic blood pressure, mm Hg & $96.1 \pm 8.4$ & $95.6 \pm 10.1$ & 0.34 & 0.74 \\
Diastolic blood pressure, mm Hg & $64.1 \pm 7.3$ & $62.6 \pm 7.1$ & 1.36 & 0.18 \\
Glucose, mmol/l & $4.93 \pm 0.48$ & $5.05 \pm 0.40$ & -1.43 & 0.16 \\
Triglycerides, mmol/l & $1.44 \pm 0.43$ & $1.31 \pm 0.38$ & 2.65 & $<0.01$ \\
Total cholesterol, mmol/l & $4.19 \pm 0.68$ & $4.05 \pm 0.61$ & 1.33 & 0.19 \\
HDL-cholesterol, mmol/l & $1.45 \pm 0.19$ & $1.56 \pm 0.44$ & -1.67 & 0.10 \\
LDL-cholesterol, mmol/l & $2.07 \pm 0.53$ & $1.93 \pm 0.63$ & 1.69 & 0.10 \\
IGFBP1, ng/ml & $9.31 \pm 19.2$ & $7.5 \pm 16.9$ & 0.52 & 0.60 \\
Insulin, pmol/l & $99.3 \pm 50.7$ & $96.5 \pm 41.0$ & 0.55 & 0.58 \\
HOMA-IR & $3.2 \pm 1.8$ & $3.1 \pm 1.3$ & 0.48 & 0.63 \\
RBP4, $\mu$ g/ml & $16.9 \pm 8.3$ & $18.1 \pm 8.0$ & -1.01 & 0.32 \\
Leptin, ng/ml & $30.7 \pm 14.8$ & $28.9 \pm 13.9$ & 1.57 & 0.12 \\
Energy, kcal/day & $2,384 \pm 568$ & $1,757 \pm 387$ & 4.80 & $<0.00006$ \\
Protein intake, g/day & $80.0 \pm 33.2$ & $69.7 \pm 15.4$ & 2.08 & 0.05 \\
Lipid intake, g/day & $82.2 \pm 30.6$ & $72.1 \pm 22.5$ & 2.06 & 0.05 \\
Carbohydrate intake, g/day & $302 \pm 80.4$ & $203 \pm 56.0$ & 9.10 & $<0.0000001$ \\
Fructose intake, g/day & $110 \pm 38.6$ & $11.4 \pm 12.0$ & 18.1 & $<0.0000001$ \\
\hline
\end{tabular}

Table 2. Changes in liver steatosis

\begin{tabular}{lllllll}
\hline & \multicolumn{2}{l}{ After fructose restriction } & \multirow{2}{*}{ Chi } & \multirow{2}{*}{ p value } \\
\cline { 2 - 4 } & no liver steatosis & slight & moderate & & & \\
\hline Slight NAFLD $(\mathrm{n}=22)$ & $4(18.2 \%)$ & $18(81.8 \%)$ & none & & 54.2 & $<0.00001$ \\
Moderate NAFLD $(\mathrm{n}=11)$ & none & $4(36.4 \%)$ & $7(63.6 \%)$ & & \\
Severe NAFLD $(\mathrm{n}=4)$ & none & $1(25 \%)$ & $3(75 \%)$ & & \\
\hline
\end{tabular}

\section{Results}

All 54 children included in the study finished intervention and had adherence to fructose restriction higher than $80 \%$. After the restriction, triglyceride levels decreased from $1.44 \pm$ 0.43 to $1.31 \pm 0.38 \mathrm{mmol} / \mathrm{l}$ ( $\mathrm{p}<0.01$ ), but no changes in BMI, waist girth, lipid, HOMA-IR, RBP4, IGFBP1, and leptin levels were found (table 1).

In the present study, our indication to restrict foods and drinks rich in fructose corn syrup was accompanied by the recommendation for no other modification of food intake. However, the analysis showed that the participants decreased calorie intake (table 1).

\section{Liver Steatosis}

The ultrasound studies showed that liver steatosis before intervention was negative in 17 children, slight in 22 , moderate in 11 , and severe in 4 . After dietary intervention, a clear improvement was found; steatosis was negative in 18 , slight in 26 , moderate in 10 , and nobody showed a severe grade $(\mathrm{p}<0.00001)$ (table 2$)$.

At the basal evaluation we found that with increased steatosis HOMA-IR was also increased $(\mathrm{p}<0.02)$ (table 3). 
Ibarra-Reynoso et al.: Effect of Restriction of Foods with High Fructose Corn Syrup Content on Metabolic Indices and Fatty Liver in Obese Children

Table 3. ANOVA for factors related with basal liver steatosis

\begin{tabular}{llllll}
\hline & $\begin{array}{l}\text { None } \\
(\mathrm{n}=17)\end{array}$ & $\begin{array}{l}\text { Slight } \\
(\mathrm{n}=22)\end{array}$ & $\begin{array}{l}\text { Moderate and severe } \\
(\mathrm{n}=15)\end{array}$ & $\mathrm{f}$ \\
\hline Age, years & $9.0 \pm 1.50$ & $8.77 \pm 1.51$ & $9.33 \pm 1.29$ & 0.67 & 0.52 \\
BMI, kg/m & $25.7 \pm 1.92$ & $26.1 \pm 2.57$ & $27.4 \pm 2.30$ & 1.82 & 0.17 \\
Waist girth, cm & $86.1 \pm 5.61$ & $85.8 \pm 7.34$ & $89.6 \pm 8.68$ & 1.40 & 0.26 \\
Systolic blood pressure, mm Hg & $96.5 \pm 8.62$ & $93.9 \pm 7.09$ & $98.7 \pm 9.54$ & 1.47 & 0.24 \\
Diastolic blood pressure, mm Hg & $63.2 \pm 3.93$ & $63.9 \pm 8.01$ & $65.3 \pm 9.35$ & 0.33 & 0.72 \\
Glucose, mmol/l & $4.90 \pm 0.41$ & $4.83 \pm 0.43$ & $5.11 \pm 0.59$ & 1.52 & 0.23 \\
Triglycerides, mmol/l & $1.42 \pm 0.36$ & $1.43 \pm 0.42$ & $1.48 \pm 0.52$ & 0.07 & 0.93 \\
Total cholesterol, mmol/l & $3.97 \pm 0.63$ & $4.22 \pm 0.51$ & $4.35 \pm 0.90$ & 1.33 & 0.27 \\
HDL-cholesterol, mmol/l & $1.35 \pm 0.18$ & $1.40 \pm 0.18$ & $1.41 \pm 0.17$ & 2.07 & 0.08 \\
LDL-cholesterol, mmol/l & $1.94 \pm 0.43$ & $2.08 \pm 0.43$ & $2.20 \pm 0.74$ & 0.95 & 0.39 \\
IGFBP1, ng/ml & $7.16 \pm 17.7$ & $11.96 \pm 20.7$ & $7.87 \pm 19.1$ & 0.35 & 0.71 \\
Insulin, pmol/l & $101 \pm 47.2$ & $82.2 \pm 39.9$ & $124 \pm 61.2$ & 3.22 & $<0.04^{\mathrm{a}}$ \\
HOMA-IR & $3.13 \pm 1.58$ & $2.47 \pm 1.25$ & $4.15 \pm 2.38$ & 4.2 & $<0.02^{\mathrm{b}}$ \\
RBP4, $\mu$ g/ml & $14.7 \pm 5.6$ & $19.1 \pm 11.1$ & $16.2 \pm 48.6$ & 1.42 & 0.25 \\
Leptin, ng/ml & $25.4 \pm 6.5$ & $30.9 \pm 16.6$ & $36.5 \pm 17.1$ & 2.37 & 0.10 \\
Energy, kcal/day & $2,231 \pm 471$ & $2,199 \pm 683$ & $2,213 \pm 472$ & 0.01 & 0.98 \\
Protein intake, g/day & $87.2 \pm 51.9$ & $75.6 \pm 20.7$ & $78.1 \pm 18.4$ & 0.61 & 0.55 \\
Lipid intake, g/day & $85.4 \pm 27.2$ & $79.6 \pm 38.2$ & $82.5 \pm 22.4$ & 0.17 & 0.85 \\
Carbohydrate intake, g/day & $306 \pm 82.3$ & $302 \pm 79.6$ & $298 \pm 84.9$ & 0.04 & 0.96 \\
Fructose intake, g/day & $114 \pm 34.2$ & $111 \pm 36.8$ & $104 \pm 46.8$ & 0.28 & 0.75 \\
\hline
\end{tabular}

aSlight vs. moderate and severe, $\mathrm{p}<0.01$.

${ }^{\mathrm{b}}$ Slight vs. moderate and severe, $\mathrm{p}<0.005$.

After 6 weeks, higher gradation of steatosis was associated with higher systolic blood pressure ( $p<0.03)$, diastolic blood pressure $(\mathrm{p}<0.03)$, HOMA-IR $(\mathrm{p}<0.007)$, and marginally higher waist girth $(\mathrm{p}=0.06)$ (table 4$)$.

\section{Factors Associated with Metabolic Changes}

We analyzed the factors associated with the changes. $\Delta$ fructose intake was associated with $\Delta$ HDL-cholesterol $(\mathrm{p}<0.04)$ and $\Delta$ triglycerides $(\mathrm{p}<0.006)$ (table 5). The $\Delta$ HOMA-IR was associated with $\Delta$ leptin levels $(\mathrm{p}<0.03) . \Delta$ RBP 4 was associated with $\Delta$ total cholesterol $(\mathrm{p}<0.004) . \Delta$ leptin level was associated with $\Delta$ triglycerides $(\mathrm{p}<0.006)$ and $\Delta$ BMI $(\mathrm{p}<0.03)$.

\section{Discussion}

The influence of fructose on the physiopathology of children's obesity has been demonstrated by experimental and clinical studies [28]. Therefore, weight reduction programs may be reinforced with emphasis in lower fructose intake. In this study, we examined the effect of the elimination of food and drinks rich in fructose corn syrup, recommending not to make any other food modifications. However, inadvertently for the children, this brought about reduced caloric intake. After 6 weeks, energy and carbohydrate intake decreased by $26.3 \%$ and $32.8 \%$, respectively. The reported diminution of caloric intake may be explained by the reduction of the well-known orexigenic effect of sweet meals [29].

This unplanned reductionof caloric intake, however, did not induce a significant weight loss. We do not consider methodological explanations for this because the personnel involved was the same for evaluation before and after intervention, but it is important to remark that the 24-hour dietary recall can be under-reported as we used self-reported data. This lacking 
Table 4. ANOVA for factors related with liver steatosis after diet

\begin{tabular}{llllll}
\hline & $\begin{array}{l}\text { None } \\
(\mathrm{n}=17)\end{array}$ & $\begin{array}{l}\text { Slight } \\
(\mathrm{n}=22)\end{array}$ & $\begin{array}{l}\text { Moderate and severe } \\
(\mathrm{n}=15)\end{array}$ & $\mathrm{f}$ \\
\hline Age, years & $8.94 \pm 1.55$ & $8.69 \pm 1.44$ & $9.9 \pm 0.87$ & 2.72 & 0.08 \\
BMI, kg/m & $25.9 \pm 2.28$ & $25.8 \pm 2.82$ & $28.1 \pm 3.37$ & 2.65 & 0.08 \\
Waist girth, cm & $86.8 \pm 5.61$ & $85.1 \pm 7.95$ & $91.6 \pm 7.23$ & 2.99 & 0.06 \\
Systolic blood pressure, mm Hg & $94.7 \pm 7.76$ & $93.3 \pm 9.05$ & $103 \pm 13.6$ & 3.79 & $<0.03^{\mathrm{c}, \mathrm{d}}$ \\
Diastolic blood pressure, mm Hg & $62.8 \pm 6.24$ & $60.6 \pm 6.38$ & $67.5 \pm 8.58$ & 3.78 & $<0.03^{\mathrm{e}}$ \\
Glucose, mmol/l & $5.04 \pm 0.44$ & $5.05 \pm 0.35$ & $5.07 \pm 0.48$ & 0.01 & 0.99 \\
Triglycerides, mmol/l & $1.37 \pm 0.45$ & $1.28 \pm 0.38$ & $1.25 \pm 0.28$ & 0.41 & 0.67 \\
Total cholesterol, mmol/l & $4.19 \pm 0.61$ & $3.93 \pm 0.61$ & $4.12 \pm 0.12$ & 1.02 & 0.37 \\
HDL-cholesterol, mmol/l & $1.47 \pm 0.25$ & $1.63 \pm 0.59$ & $1.51 \pm 0.12$ & 0.71 & 0.50 \\
LDL-cholesterol, mmol/l & $2.07 \pm 0.72$ & $1.80 \pm 0.56$ & $2.02 \pm 0.62$ & 1.13 & 0.33 \\
IGFBP1, ng/ml & $7.67 \pm 17.4$ & $9.35 \pm 19.6$ & $2.18 \pm 2.09$ & 0.64 & 0.53 \\
Insulin, pmol/l & $89.1 \pm 31.7$ & $87.6 \pm 39.8$ & $133 \pm 42.9$ & 5.63 & $<0.006^{\mathrm{a}, \mathrm{b}}$ \\
HOMA-IR & $2.82 \pm 1.07$ & $2.77 \pm 1.27$ & $4.21 \pm 1.35$ & 5.50 & $<0.007^{\mathrm{a}, \mathrm{b}}$ \\
RBP4, $\mu \mathrm{g} / \mathrm{ml}$ & $17.3 \pm 7.45$ & $18.1 \pm 7.03$ & $19.5 \pm 10.1$ & 0.23 & 0.79 \\
Leptin, ng/ml & $26.4 \pm 7.74$ & $29.5 \pm 16.9$ & $32.1 \pm 14.2$ & 0.56 & 0.57 \\
Energy, kcal/day & $1,740 \pm 499$ & $1,713 \pm 341$ & $1,730 \pm 403$ & 0.02 & 0.98 \\
Protein intake, g/day & $70.8 \pm 14.5$ & $68.8 \pm 17.0$ & $70.3 \pm 13.8$ & 0.09 & 0.91 \\
Lipid intake, g/day & $72.95 \pm 25.0$ & $72.5 \pm 20.9$ & $69.8 \pm 24.1$ & 0.06 & 0.94 \\
Carbohydrate intake, g/day & $201 \pm 68.0$ & $202 \pm 50.5$ & $208 \pm 54.1$ & 0.04 & 0.96 \\
Fructose intake, g/day & $9.78 \pm 9.49$ & $12.8 \pm 14.7$ & $10.7 \pm 8.46$ & 0.34 & 0.72 \\
\hline
\end{tabular}

${ }^{a}$ None vs. moderate and severe, $\mathrm{p}<0.005$.

${ }^{b}$ Slight vs. moderate and severe, $\mathrm{p}<0.002$.

${ }^{\mathrm{c}}$ None vs. moderate and severe, $\mathrm{p}<0.03$.

${ }^{\mathrm{d}}$ Slight vs. moderate and severe, $\mathrm{p}<0.009$.

eslight vs. moderate and severe, $\mathrm{p}<0.008$.

Table 5. Multiple stepwise regression coefficients for factors associated with metabolic changes in the group with fructose restriction

\begin{tabular}{|c|c|c|c|c|}
\hline Dependent variable & Regressor & Beta \pm S.E. & $\mathrm{t}$ & $\mathrm{p}$ \\
\hline$\Delta$ diet fructose, $\mathrm{g} /$ day & $\begin{array}{l}\Delta \text { triglycerides, mmol/l } \\
\Delta \text { HDL-cholesterol, mmol/l }\end{array}$ & $\begin{array}{l}0.4 \pm 0.1 \\
-0.2 \pm 0.1\end{array}$ & $\begin{array}{l}2.9 \\
-2.1\end{array}$ & $\begin{array}{l}<0.006 \\
<0.04\end{array}$ \\
\hline$\Delta$ HOMA-IR & $\Delta$ leptin, $\mathrm{ng} / \mathrm{ml}$ & $0.3 \pm 0.1$ & 2.3 & $<0.03$ \\
\hline$\Delta \mathrm{RBP} 4, \mu \mathrm{g} / \mathrm{ml}$ & $\Delta$ total cholesterol, $\mathrm{mmol} / \mathrm{l}$ & $0.4 \pm 0.1$ & 3.0 & $<0.004$ \\
\hline$\Delta$ leptin, $\mathrm{ng} / \mathrm{ml}$ & $\begin{array}{l}\Delta \text { triglycerides, mmol/l } \\
\Delta \mathrm{BMI}, \mathrm{kg} / \mathrm{m}^{2}\end{array}$ & $\begin{array}{l}0.3 \pm 0.1 \\
0.3 \pm 0.1\end{array}$ & $\begin{array}{l}2.8 \\
2.2\end{array}$ & $\begin{array}{l}<0.006 \\
<0.03\end{array}$ \\
\hline
\end{tabular}

weight change is a frequent observation during treatment of obesity that may have several explanations: During caloric restriction there is an acute adaptation of energy expenditure that varies in different populations [30]; this adaptive decrease of tissue metabolism depends on genetic characteristics [31]. A compensatory reduction of activity also occurs during caloric restriction [32]. Additionally, dietary changes may modify the gut microbiota with an effect on nutrient absorption [33]. Yet, it is also possible that our data are falsified by underreporting as a result of using a self-reported 24-hour dietary recall.

Systematic reviews and meta-analyses of controlled trials under isoenergetic conditions showed no association between the reduced intake of dietary sugars and changes in BMI [34]. 
Ibarra-Reynoso et al.: Effect of Restriction of Foods with High Fructose Corn Syrup Content on Metabolic Indices and Fatty Liver in Obese Children

Possible genetic or ethnic differences may modify the metabolic actions of fructose $[35,36]$. It is also possible that other components in diet may interact with fructose for the metabolic outcome, as reported for the sodium content in diet [37].

Our results did not show any effect of fructose restriction on insulin resistance. This agrees with a recent report in adults, in which the replacement of sugar by artificially sweetened beverages induced a significant decrease in intrahepatic fat, with no changes in body weight or insulin resistance [38]. Our data difered from those of Lustig et al [20] who found weight loss and metabolic improvement with only 9 days of isocaloric substitution of fructose with starch.

After 6 weeks of fructose restriction, in spite of the unchanged insulin sensitivity, triglycerides diminished. This indicates that the effect of excess fructose consumption on triglycerides may be reverted with no changes in BMI or insulin sensitivity.

The frequency of fatty liver in adolescents varies in different populations. In Hispanic populations this alteration is widespread [39]. In a previous work, we found that in obese children not selected for high fructose consumption the frequency of fatty liver was $42.6 \%$ [40]. In the present study, that focused on children with fructose consumption $>70 \mathrm{~g} /$ day, $73.1 \%$ of participants presented with fatty liver. After intervention, an important decrease in liver steatosis was observed. Previous reports suggest changes on steatosis depend not only on obesity but also on the metabolic condition [41]. This finding is in agreement with previous work in which liver fat may diminish at an early stage of caloric [42] or fructose restriction [43]. As expected, we found HOMA-IR associated with the progression of liver steatosis.

In this study, metabolic changes induced by food restriction are consistent with expected interactions, e.g., fructose restriction leads to decreases in triglyceride and increases in HDLcholesterol levels. The positive association of HOMA-IR with leptin changes can be explained by the dependence of both factors on obesity. The association of RBP4 and total cholesterol has been also reported [44]. The relationship of leptin levels with triglycerides and BMI is consistent with dependence of leptin levels on adiposity [45].

A limitation of our study is that restricting foods and beverages rich in fructose corn syrup inadvertently brings about changes in food, leading to reduced caloric diet. Finally, the present investigation is a non-controlled and non-randomized study carried out in normal obese children, with the opportunity to carry out modifications in their diet. This fact limits the extrapolation of results to the whole population.

\section{Conclusions}

In summary we found that fructose restriction was associated with diminution of triglyceride levels and an important diminution of liver steatosis. However, our results did not show any changes of body weight or insulin resistance, which may be explained by adaptive changes in metabolic expenditure.

\section{Ethics Approval and Consent to Participate}

When candidates met inclusion criteria, the nature and purpose of the study was explained to them and at least one of their parents. Both children and parents signed informed consent; confidentiality of results was guaranteed. The study was approved by the Ethics Committee of the Institution (CE-2013-9).

\section{Funding}

This study was supported by a grant from CONACYT (GTO-2012-C03-195255). 


\section{Authors' Contributions}

LIR, JMM, and MEGS designed the research; LIR and HLLL oversaw data collection; HLLL was responsible for the dietary restriction; LIR and JMM performed statistical analyses and wrote the manuscript; LIR, HLLL, MEGS and JMM were involved in revision of the manuscript. All authors read and approved the final manuscript.

\section{Disclosure Statement}

The authors declare that they have no competing interests.

\section{References}

1 Bray GA, Nielsen SJ, Popkin BM: Consumption of high-fructose corn syrup in beverages may play a role in the epidemic of obesity. Am J Clin Nutr 2004;79:537-543.

2 Stanhope KL, Schwarz JM, Keim NL, Griffen SC, Bremer AA, Graham JL, Hatcher B, Cox CL, Dyachenko A, Zhang W, McGahan JP, Seibert A, Krauss RM, Chiu S, Schaefer EJ, Ai M, Otokozawa S, Nakajima K, Nakano T, Beysen C, Hellerstein MK, Berglund L, Havel PJ: Consuming fructose-sweetened, not glucose-sweetened, beverages increases visceral adiposity and lipids and decreases insulin sensitivity in overweight/obese humans. J Clin Invest 2009;119:1322-1334.

3 Stanhope KL, Havel PJ: Fructose consumption: potential mechanisms for its effects to increase visceral adiposity and induce dyslipidemia and insulin resistance. Curr Opin Lipidol 2008;19:16-24.

4 Jin R, Le NA, Liu S, Farkas Epperson M, Ziegler TR, Welsh JA, Jones DP, McClain CJ, Vos MB: Children with NAFLD are more sensitive to the adverse metabolic effects of fructose beverages than children without NAFLD. J Clin Endocrinol Metab 2012;97:E1088-1098.

5 Brown CM, Dulloo AG, Yepuri G, Montani JP: Fructose ingestion acutely elevates blood pressure in healthy young humans. Am J Physiol Regul Integr Comp Physiol 2008;294:730-737.

6 Thuy S, Ladurner R, Volynets V, Wagner S, Strahl S, Königsrainer, Maier KP, Bischoff SC, Bergheim I: Nonalcoholic fatty liver disease in humans is associated with increased plasma endotoxin and plasminogen activator inhibitor 1 concentrations and with fructose intake. J Nutr 2008;138:1452-1455.

7 Abdelmalek MF, Lazo M, Horska A, Bonekamp S, Lipkin EW, Balasubramanyam A, Bantle JP, Johnson RJ, Diehl AM, Clark JM: Higher dietary fructose is associated with impaired hepatic adenosine triphosphate homeostasis in obese individuals with type 2 diabetes. Hepatology 2012;56:952-960.

8 Neuschwander-Tetri BA: Carbohydrate intake and nonalcoholic fatty liver disease. Curr Opin Clin Nutr Metab Care 2013;16:446-452.

9 Lonardo A, Bellentani S, Ratziu V, Loria P: Insulin resistance in non-alcoholicsteatohepatitis: necessary but not sufficient - death of a dogma from analysis of therapeutic studies? Expert Rev Gastroenterol Hepatol 2011;5: 279-289.

10 Goyal NP, Schwimmer JB: The progression and natural history of pediatric nonalcoholic fatty liver disease. Clin Liver Dis 2016;20:325-338.

11 Schwimmer J, Deutsch R, Kahen T, Lavine J, Stanley C, Behling C: Prevalence of fatty liver in children and adolescents. Pediatrics 2006;118:1388-1393.

12 Kotronen A, Lewitt M, Hall K, Brismar K, Yki-Jarvinen H: Insulin-like growth factor binding protein 1 as a novel specific marker of hepatic insulin sensitivity. J Clin Endocrinol Metab 2008;93:4867-4872.

13 Clark JM, Diehl AM: Hepatic steatosis and type 2 diabetes mellitus. Curr Diab Rep 2002;2:210-215.

14 Perseghin G, Bonfanti R, Magni S, Lattuada G, De Cobelli F, Canu T, Esposito A, Scifo P, Ntali G, Costantino F, Bosio L, Ragogna F, Del Maschio A, Chiumello G, Luzi L: Insulin resistance and whole body energy homeostasis in obese adolescents with fatty liver disease. Am J Physiol Endocrinol Metab 2006;291:697-703.

15 Crespo M, Lappe S, Feldstein AE, Alkhouri N: Similarities and differences between pediatric and adult nonalcoholic fatty liver disease. Metabolism 2016;65:1161-1171.

16 Kleiner DE, Makhlouf HR: Histology of nonalcoholic fatty liver disease and nonalcoholic steatohepatitis in adults and children. Clin Liver Dis 2016;20:293-312.

17 Mencin AA, Loomba R, Lavine JE: Caring for children with NAFLD and navigating their care into adulthood. Nat Rev Gastroenterol Hepatol 2015;12:617-628.

18 Madero M, Arriaga JC, Jalal D, Rivard C, McFann K, Pérez O, Vázquez A, Ruiz A, Lanaspa MA, Jimenez CR, Johnson RJ, Lozada LG: The effect of two energy-restricted diets, a low-fructose diet versus a moderate natural fructose diet, on weight loss and metabolic syndrome parameters: a randomized controlled trial. Metabolism 2011;60: 1551-1559.

19 Madero M, Rodríguez Castellanos FE, Jalal D, Villalobos-Martín M, Salazar J, Vazquez-Rangel A, Johnson RJ, Sánchez-Lozada LG: A pilot study on the impact of a low fructose diet and allopurinol on clinic blood pressure among overweight and prehypertensive subjects: a randomized placebo controlled trial. J Am Soc Hypertens $2015 ; 9: 837-844$. 
Ibarra-Reynoso et al.: Effect of Restriction of Foods with High Fructose Corn Syrup

Content on Metabolic Indices and Fatty Liver in Obese Children

20 Lustig RH, Mulligan K, Noworolski SM, Tai VW, Wen MJ, Erkin-Cakmak A, Gugliucci A, Schwarz J-M: Isocaloric fructose restriction and metabolic improvement in children with obesity and metabolic syndrome. Obesity (Silver Spring) 2016;24:453-460.

21 Cole TJ, Bellizzi MC, Flegal KM, Dietz WH: Establishing a standard definition for child overweight and obesity worldwide: international survey. BMJ 2000;320:1240-1243.

22 National Health and Nutrition Examination Survey: Anthropometry Procedures Manual. 2007. www.cdc.gov/ nchs/data/nhanes/bm.pdf (last accessed July 25, 2017).

23 Kurtoğlu S, Hatipoğlu N, Mazıcıoğlu M, Kendirici M, Keskin M, Kondolot M: Insulin resistance in obese children and adolescents: homa-ir cut-off levels in the prepubertal and pubertal periods. J Clin Res Pediatr Endocrinol 2010;2:100-106.

24 Saadeh S, Younossi ZM, Remer EM, Gramlich T, Ong JP, Hurley M, Mullen KD, Cooper JN, Sheridan MJ: Utility of radiological imaging in nonalcoholic fatty liver disease. Gastroenterology 2002;123:745-750.

25 Mittelstaedt C: General Ultrasound. New York, Churchill Livingstone, 1992.

26 Matthews RH, Pehrsson PR, Farhat M: Sugar Content of Selected Foods: Individual and Total Sugars. Washington, D.C, United States Department of Agriculture, 1987.

27 Hernández JE, González L, Rosales E: Sistema de Evaluación de Hábitos Nutricionales y Consumo de Nutrimentos. SNUT. Instituto Nacional de Salud Pública. Centro de Investigación en Salud Poblacional. www.insp. $m x /$ snut2003/ (last accessed July 25, 2017).

28 Morgan RE: Does consumption of high-fructose corn syrup beverages cause obesity in children? Pediatr Obes 2013;8:249-254.

29 Tamam S, Bellissimo N, Patel BP, Thomas SG, Anderson GH: Overweight and obese boys reduce food intake in response to a glucose drink but fail to increase intake in response to exercise of short duration. Appl Physiol Nutr Metab 2012;37:520-529.

30 André C. Carpentier. Acute adaptation of energy expenditure predicts diet-induced weight loss: revisiting the thrifty phenotype. Diabetes 2015;64:2714-2716.

31 Ghosh S, Dent R, Harper ME, Stuart J, McPherson R: Blood gene expression reveal pathway differences between diet-sensitive and resistant obese subjects prior to caloric restriction. Obesity (Silver Spring) 2011;19:457463.

32 Westerterp KR: Control of energy expenditure in humans. Eur J Clin Nutr 2017;71:340-344.

33 Rosenbaum M, Knight R, Leibel RL: The gut microbiota in human energy homeostasis and obesity. Trends Endocrinol Metab 2015;26:493-501.

34 Te Morenga L, Mallard S, Mann J: Dietary sugars and body weight: systematic review and meta-analyses of randomised controlled trials and cohort studies. BMJ 2012;346:e7492.

35 Goran MI, Walker R, Allayee H: Genetic-related and carbohydrate-related factors affecting liver fat accumulation. Curr Opin Clin Nutr Metab Care 2012;15:392-396.

36 Thompson FE, McNeel TS, Dowling EC, Midthune D, Morrissette M, Zeruto CA: Interrelationships of added sugars intake, socioeconomic status, and race/ethnicity in adults in the United States: National Health Interview Survey, 2005. J Am Diet Assoc 2009;109:1376-1383.

37 Hernández-Ríos R, Hernández-Estrada S, Cruz-Robles D, Hernández-Lobato S, Villalobos-Martín M, Johnson RJ, Rodríguez-Castellanos F, Salazar J, García-Arroyo F, Sánchez-Lozada LG, Madero M: Low fructose and low salt diets increase mitochondrial DNA in white blood cells of overweight subjects. Exp Clin Endocrinol Diabetes 2013;121:535-538.

38 Campos V, Despland C, Brandejsky V, Kreis R, Schneiter P, Chiolero A, Boesch C, Tappy L: Sugar- and artificially sweetened beverages and intrahepatic fat: a randomized controlled trial. Obesity (Silver Spring) 2015;23: 2335-2339.

39 Jin R, Le NA, Cleeton R, Sun X, Cruz Muños J, Otvos J, Vos MB: Amount of hepatic fat predicts cardiovascular risk independent of insulin resistance among Hispanic-American adolescents. Lipids Health Dis 2015;14:39.

40 Ibarra-Reynoso LR, Pisarchyk L, Pérez-Luque EL, Garay-Sevilla ME, Malacara JM: Whole body and hepatic insulin resistance in obese children. PLoS One 2014;9:e113576.

41 Kleiner DE, Makhlouf HR: Histology of nonalcoholic fatty liver disease and nonalcoholic steatohepatitis in adults and children. Clin Liver Dis 2016;20:293-312.

42 Promrat K, Kleiner DE, Niemeier HM, Jackvony E, Kearns M, Wands JR, Fava JL, Wing RR: Randomized controlled trial testing the effects of weight loss on nonalcoholic steatohepatitis. Hepatology 2010;51:121129.

43 Volynets V, Machann J, Küper MA, Maier IB, Spruss A, Königsrainer A, Bischoff SC, Bergheim I: A moderate weight reduction through dietary intervention decreases hepatic fat content in patients with non-alcoholic fatty liver disease (NAFLD): a pilot study. Eur J Nutr 2013;52:527-535.

44 Siejka A, Jankiewicz-Wika J, Kołomecki K, CywińskiJ, Piestrzeniewicz K, SwiętosławskiJ, Stepien H, Komorowski J: Long-term impact of vertical banded gastroplasty (VBG) on plasma concentration of leptin, soluble leptin receptor, ghrelin, omentin-1, obestatin, and retinol binding protein 4 (RBP4) in patients with severe obesity. Cytokine 2013;64:490-493.

45 Hassink SG, Sheslow DV, de Lancey E, Opentanova I, Considine RV, Caro JF: Serum leptin in children with obesity: relationship to gender and development. Pediatrics 1996;98:201-203. 